\title{
Editorial: Ageing \& Society in its majority
}

Past twenty-one years of age, a striking new cover and a new editor: is Ageing \& Society about to be radically transformed? Not at all, but over the next five years it will aim to be even better at the things it has been doing well. To stretch the life course analogy, having reached a 'mature age' and with an accomplished juvenilia, the paths that promise most are well defined. The achievement to date has been impressive, and the strong foundation creates a larger potential. It is in this context and spirit that I take up the editorship in succession to Bill Bytheway. The editorial policy will of course be frequently reexamined and refined, but neither the editorial board nor I wish to see the journal's core ambitions and values change. My aims are to help authors achieve these to an even higher standard, and particularly to raise the title's reputation for originality, for the quality of the research that it reports, and for its standards of communication. The goal is to raise the 'impact' of Ageing \& Society, in citation indicators and, more importantly, in its contributions to understanding and to the formation of opinion and policy.

What are these core ambitions and values? They have been remarkably consistent since the conception of the journal, and were very well elaborated on the first page by Malcolm Johnson, the founding editor: 'Our first concern will be with developing a greater understanding of human ageing whether it be through theoretical refinement, methodological development, the results of empirical studies, literature reviews or policy analyses. In seeking a balance among these interests, care will also be taken to represent as wide a range as possible of disciplines and topics within the social sciences and the humanities. Equally, the international character of the journal

must be reflected ... in a truly universal interest in the diversity of cultural influences on ageing processes. With such criteria, and with an audience drawn from many backgrounds and perspectives, it is more important than usual for the contributions to be readily comprehensible' (Johnson r98I: I). It is to the great credit of Malcolm Johnson and the contributors to the first eleven volumes that this is exactly what was achieved during the first decade.

In I 984 , the journal's strong start justified an expansion from three to four issues each year (Johnson i 984: i). Peter Coleman became the 
review editor and began to elaborate the review section into an important vehicle for achieving the stated aims. By I992, on his succession as editor, he remarked that the journal 'has established itself as one of the most genuinely international in the field of ageing studies. It has also demonstrated its multi-disciplinary character by publishing articles from a wide spectrum of academic disciplines and perspectives. Authors have been encouraged to write in ways which while remaining scholarly also allow their work to be read with profit by readers whose primary expertise may lie elsewhere' (Coleman i 992: I). He also noted that the journal had fostered broadly conceived and directed reports, helped researchers acquire an understanding of the work being carried out in adjacent fields, and encouraged contributions that bridged the divide between 'thinkers' and 'practitioners'. Not surprisingly, given Peter's own contributions and numerous European contacts, subsequent years saw many strong articles from European psychology and social gerontology.

In 1996 the journal increased its frequency of publication from four to six issues each year. The editorial at that time noted that it is particularly important to hold on to [the promotion of multidisciplinarity] at the present, when interest in ageing issues is rising dramatically. As academic and research communities grow, so inevitably the specialisation of work and outlets intensifies.... It remains central to our credo that the best gerontological understanding and the sanest and most effective policies for the welfare of older people require unusual breadth. When those in specialised professional, academic or policy-making fields can place the well being of older people in a broad societal context, then fewer divisive, ephemeral and merely fashionable statements and changes will be made (Coleman and Warnes i996: i-ii).

Ken Blakemore and Bill Bytheway succeeded as editors in I 997, and affirmed their commitment to the journal's aims, which they neatly distilled to being 'international, multi-disciplinary, scholarly, accessible and relevant'. They also referred to the changing social, policy and research environments, which had brought the 'globalisation of trends in consumption', moved ageing issues closer to the centre of government policy, and a flood of studies on 'society and culture' (Blakemore and Bytheway I997: г). Bill continued as sole editor after i998, and has been notably successful in generating articles that viewed issues from older people's perspectives and that have identified and combated ageism.

The proliferation and specialisation of academic journals has touched gerontology more than most academic areas, for 'ageing issues' are 
now a leading policy concern and this, in turn, has brought our themes raised prominence in the agenda of many research funding organisations. A growing fraction of research is explicitly for policy formation and implementation, which brings strengths, dangers and probably yet more specialisation. One positive response to increased funding (as evident for two decades in the United States), is the attraction to gerontology of more excellent researchers and previously uninvolved disciplines. There will as a result be new findings and fresh understanding. This journal has and will continue to play a distinctive and valuable role in being the prime outlet for the communication of specialist findings to a wide research and policy audience.

\section{Practicalities}

At the time of writing, I had reviewed around 20 new submissions and many more articles undergoing revision. There has been much encouragement in what I've seen. At least four types of strong article are being submitted more frequently than before:

- Well explained reports with original gerontological findings from large, representative national surveys or panel studies, as in The Netherlands and The United Kingdom. Until recently these resources have been much less developed in Europe than in the United States. It will be instructive for us all to be able to compare alternative national findings and perspectives on key gerontological issues.

- Original and focussed empirical contributions from other continents, particularly central America and Asia. While general views of demographic and societal ageing in these and other world regions have been forthcoming for two decades, there are now signs of more primary research and that local gerontological debates are asserting their independence from Anglo-American and European derivations.

- Papers with original insights and substance from anthropologists and from other social scientists and health care researchers that are applying in appropriate and sophisticated ways ethnographic research methodologies.

- Papers with strong experiential content on, for example, what it is like either to become or to be old, not least with reference to the expectations of one's children and their families; or about the experience of stigmatising and demeaning treatment from professional and volunteer care workers. 
There are still considerable gaps. There should be more papers from economists, political scientists, anthropologists and educationalists, and from the humanities and the biological and clinical sciences. Can the number of papers from Africa, Brasil, France, Italy, Russia, India, Indonesia and Japan be increased? Why is there so little research about what older people actually do, how they spend their time and money, whom they interact with, or about their views and aspirations?

There are of course submitted papers that prompt dismay, usually because the authors have not sufficiently attended to either the journal's style conventions or had consideration for its multidisciplinary and international readership. Unexplained national acronyms are the most obvious sign, but the British author who uses without definition standard terms in our vocabulary such as 'pensioner', 'social housing' or 'care assessment', or the United States authors who similarly write 'baby boomers', 'high school education', 'latino' or 'generation $\mathrm{X}$ ', have not recognised that at best their meaning is equivocal outside their own countries.

Where authors have something original, distinct or valuable to say, unusual efforts will be made to help bring the articles to publishable standard, especially from inexperienced or non-native English writers. The complement, if all goes well, will be a growing reluctance to do the capable author's job. Readers, contributors and referees can help in this. My intention is that the 'notes for contributors' on the journal's web site pages (on the Cambridge University Press site at www. cambridge.org) will be expanded, as with articles about writing for an international readership and the preparation of tables and figures. Your views and suggestions will be greatly appreciated. This is just one way in which the contributions to the journal will achieve even higher standards than before. As this occurs, it will become more important for

authors to prepare their articles with close reference to the journal's long-standing aims, ambitions, values and requirements.

\section{References}

Blakemore, K. and Bytheway, B. I997. Editorial, Ageing \& Society, I7, I-2.

Coleman, P. G. I992. Editorial, Ageing \& Society, r2, I-3.

Coleman, P. G. and Warnes, A. M. I996. Editorial, Ageing \& Society, r6, i-iv.

Johnson, M. L. i981. Editorial, Ageing \& Society, I, I-3.

Johnson, M. L. I984. Editorial, Ageing \& Society, 4, I-2.

TONY WARNES 